\title{
Políticas Educacionais: Questões e Dilemas
}

STEPHEN J. BALL, JEFFERSON MAINARDES (Org.)

SÃO PAULO: CORTEZ, 2011, 288 p.

A obra organizada por Stephen J. Ball e Jefferson Mainardes é uma coletânea de artigos de pesquisadores britânicos, brasileiros e de um argentino, e favorece amplo debate sobre as questões e os dilemas enfrentados pelas políticas educacionais contemporâneas. Stephen J. Ball, professor do Instituto de Educação da Universidade de Londres, tem várias publicações, em forma de livros e artigos, que versam sobre o campo das políticas educacionais, e é considerado pesquisador de referência sobre a temática. Jefferson Mainardes, doutor pelo mesmo instituto, é professor da Universidade Estadual de Ponta Grossa - UEPG - e, também, autor e pesquisador, tendo se dedicado principalmente a esse veio de análise.

O livro está dividido em duas partes e tem como objetivo contribuir para o avanço teórico e empírico das análises no campo das políticas educacionais, particularmente as realizadas no Brasil. Na primeira parte, constituída de seis capítulos, são apresentadas discussões metodológicas da pesquisa em políticas educacionais. Na segunda parte, com quatro capítulos, são discutidas pesquisas sobre políticas educacionais. O último capítulo constitui uma análise crítica das contribuições de Stephen J. Ball para as investigações das políticas de currículo.

Como a maior parte dos capítulos é composta de traduções de textos originalmente publicados em língua inglesa, pergunta-se: o que teriam as análises das políticas educacionais de outros países e, no caso, do Reino Unido, a contribuir com o referencial analítico para as políticas educacionais brasileiras e a lhes acrescentar? Esta é a questão que persegue o leitor-pesquisador desde o primeiro capítulo e faz que, a todo tempo, ele busque identificar as características e similaridades das influências internacionais nos contextos da política.

No capítulo 1, "Sociologia das políticas educacionais e pesquisa crítico social: uma revisão pessoal das políticas educacionais e da pesquisa em 
política educacional”, Stephen Ball se propõe a tratar da questão, no âmbito do Reino Unido, durante os últimos 15 a 20 anos. Ele argumenta haver uma transformação nos princípios de provisão social do Estado de bem-estar social para o Estado schumpeteriano, que, com a reestruturação do setor público, passa a operar sob uma nova cultura. A educação começa a conviver com discursos de excelência, efetividade, qualidade, que se refletem na gestão e no papel dos diretores na perspectiva do neoliberalismo, do novo gerencialismo e do espírito de empreendedorismo, gerando uma nova economia moral, pautada no cultivo da performatividade. $\mathrm{E}$, no que se refere às pesquisas em políticas educacionais, o autor, se aproximando da perspectiva pós-estruturalista, critica as análises que mantêm o hiato entre política e prática, bem como expressa sua preocupação com a ausência da teoria e com o empirismo descritivo nas pesquisas. Enfatiza a participação dos sujeitos, defendendo a inclusão das pessoas nas políticas e nas suas análises, e expressa clara preocupação com a justiça social.

No capítulo 2, "O detalhe e o macrocontexto: o uso da teoria centrada no Estado para explicar práticas e políticas educacionais”, Sally Power discute as análises das políticas que se utilizam das abordagens estadocêntricas e aderem a uma compreensão marxista das relações sociais que envolve o reconhecimento do Estado e sua relação com o capital, ou seja, que prioriza o macrocontexto em detrimento dos detalhes - do microcontexto. Para a autora, em vez de se pensar em macro e micro como processos dicotômicos, seria mais apropriado, à teoria centrada no Estado, demonstrar o papel que a abordagem macrocontextual exerce nos relatos mais detalhados.

Stephen Ball inicia o capítulo 3, "Intelectuais ou técnicos? O papel indispensável da teoria nos estudos educacionais”, criticando a insuficiência dos estudos educacionais no Reino Unido em razão da ignorância teórica dos campos de conhecimento. Segue questionando o papel dos pesquisadores das políticas que, a partir da década de 1980, se tornaram "pesquisadores da eficácia escolar" e "teóricos do gerenciamento" e, a partir da década de 1990, “engenheiros políticos”. Discute, então, a relação entre a teoria do gerenciamento e a pesquisa sobre eficácia escolar. Aponta como caminho para repensar os estudos educacionais, a reflexividade crítica e a alternativa pós-estrutural, com ênfase na teoria como "um veículo para pensar diferente", oferecendo uma linguagem criativa que propicie a desidentificação.

No capítulo 4, "O que fazer a respeito de valores na pesquisa social: o caso da reflexividade ética na sociologia da educação”, Sharon Gewirtz e Alan Cribb apontam que, na literatura educacional, mais especificamente na pesquisa social, não são discutidos valores e nem a sua relação com o rigor descritivo, e defendem a reflexividade ética na investigação científica. Distinguem o pesquisador como produtor de conhecimento e o pesquisador como cidadão, interessado na maneira pela qual o conhecimento é usado, argumentando que a análise das pesquisas pode apontar implicações práticas ou 
políticas. No capítulo 5, os mesmos autores abordam a questão da justiça social e a tensão entre as suas diversas facetas. Nessa relação, criticam as análises sociológicas que concebem as políticas como algo que acontece a distância, ou acima da prática. Sugerem a busca de meios para tratar adequadamente as tensões, de forma a contribuir para o trabalho dos que estão se esforçando dentro e em torno das escolas para criar políticas e práticas socialmente mais justas.

Jefferson Mainardes, Márcia das Santos Ferreira e CésarTello, no capítulo 6, “Análise de políticas: fundamentos e principais debates teórico-metodológicos”, apresentam um panorama dos principais debates teórico-metodológicos relacionados à análise de políticas educacionais, mais especificamente dos referenciais pós-estruturalistas e pluralistas, reconhecendo que no Brasil ainda são poucos os trabalhos que caminham nessa direção. Os autores destacam o trabalho dos analistas políticos e dos pesquisadores em políticas e suas relações com os critérios de utilidade e os critérios de verdade (ciência clássica). Ressaltam a relação entre as finalidades da pesquisa e a reflexividade ética, defendidos por Gewirtz e Cribb, no capítulo 4. Defendem que políticas devem ser entendidas como processo e produto, superando os modelos lineares de análise, e argumentam que os estudos de políticas poderiam obter saltos qualitativos na medida em que o referencial teórico, o posicionamento teórico e o enfoque epistemológico fossem explicitados pelos pesquisadores.

No capítulo 7, "Discursos da reforma educacional no Reino Unido e nos Estados Unidos e o trabalho dos professores”, Mag Maguire e Stephen Ball realizam uma análise comparativa das políticas reformistas ocorridas na educação nos dois países. De acordo com os autores, um dilúvio de legislação e de recomendações políticas se abateu sobre a educação, que foi culpabilizada pela situação de crise fiscal e recessão continuada em ambos os países. Valem-se da concepção de discurso para contrastar a situação do professor no contexto das reformas.

"Do modelo de gestão do Bem-Estar Social ao novo gerencialismo" é o tema do capítulo 8, assinado por Sharon Gewirtz e Stephen J. Ball. Eles analisam a situação da educação no Reino Unido, submetida a um regime de organização e de financiamento orientado pelos princípios de mercado. Os autores abordam a questão dos valores na fase do bem-estar social e na fase de mercado educacional - novo gerencialismo -, tendo como foco as mudanças discursivas nas práticas de gestão escolar e no papel do diretor como o novo gerente. Para os autores, o novo contexto não envolve apenas mudança de estrutura e incentivos. Trata-se antes de um processo transformacional que engloba novo conjunto de valores e novo ambiente moral.

O capítulo 9 versa sobre a educação no Brasil. Em "Conversão das 'almas' pela liturgia da palavra: uma análise do discurso do movimento Todos pela Educação”, Eneida Shiroma, Rosalba Maria Cardoso Garcia e Roselane 
Fátima Campos, ancoradas em Ball ${ }^{1}$, defendem a importância da análise dos processos pelos quais as políticas são produzidas e implementadas/retraduzidas, bem como dos seus efeitos e estratégias. Fazem um estudo do documento “Todos pela Educação: rumo a 2022”, o qual, pela liturgia da palavra, pretende operar uma mudança no perfil dos usuários dos serviços educacionais, difundindo uma nova maneira de ser cidadão.

No último capítulo, Alice Casimiro Lopes e Elizabeth Macedo analisam as "Contribuições de Stephen Ball para o estudo de políticas de currículo". A concepção do ciclo de políticas, defendida pelo autor², permite a análise do estudo da micropolítica institucional e disciplinar, por meio da superação do hiato entre produção e implementação, considerando o processo de recontextualização das políticas que ocorre nas escolas. Para as autoras, Ball se move na perspectiva pós-estruturalista, sem abandonar, entretanto, a perspectiva crítica na luta pela igualdade e pela justiça social. Ao chamarem a atenção para a categoria hibridismo, Lopes e Macedo apontam para a possibilidade de avançar na abordagem do ciclo de políticas mediante a construção da relação entre as determinações estruturais e a ação.

Pelo exposto, pode-se compreender que o encontro desses autores não ocorre sem um propósito. Há vários aspectos teóricos que os unem independentemente de qual território se esteja falando, tais como a preocupação com: a teoria nos estudos de políticas educacionais; as possibilidades da análise do discurso das políticas; a dicotomia entre as perspectivas macro e micro nas análises das políticas; a reflexividade ética; e, ainda, o enfoque crítico nas relações entre as políticas e a justiça social.

No decorrer da leitura e ao seu final, percebe-se que os autores dessa coletânea cumprem o que foi proposto com a sua publicação e, de certa forma, respondem à questão colocada no início da resenha, quando deixam evidente que a política não pode continuar a ser pensada nos limites de Estados-Nação, ou de fronteiras nacionais, ou seja, que ela circula por meio de incalculáveis capilaridades transnacionais. Nesse sentido, ressalta-se a importância da contribuição dos autores e pesquisadores estrangeiros, com destaque para as de ordem teórico-metodológica do ciclo de políticas de Stephen J. Ball, com a qual os demais autores dialogam, nas análises das políticas educacionais brasileiras. Suas repercussões podem ser constatadas em vários estudos e investigações nos programas de pós-graduação das nossas universidades, conforme demonstrado no levantamento (disponível em: www.upeg.br/gppepe).

O livro é um convite à leitura, indispensável àqueles pesquisadores que se dedicam ao campo das políticas educacionais no Brasil.

\section{KARLA REIS GOUVEIA}

Doutora em Educação do Programa de Pós-Graduação em Educação da Universidade Federal de Pernambuco 